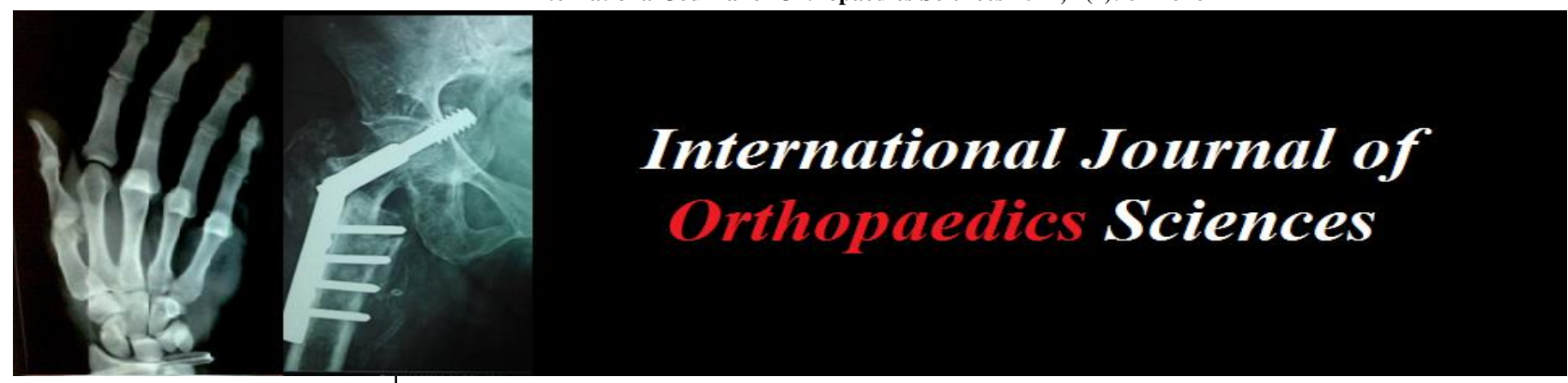

E-ISSN: 2395-1958

P-ISSN: 2706-6630

IJOS 2021; 7(2): 812-816

(C) 2021 IJOS

www.orthopaper.com

Received: 04-02-2021

Accepted: 06-03-2021

Dr. G Rishikanta Sharma

Senior Resident, Department of

Orthopaedics, Regional Institute of Medical Sciences, Imphal,

Manipur, India

Dr. Mhasesalu Tetseo

Post Graduate Trainee,

Department of Orthopaedics,

Regional Institute of Medica

Sciences, Imphal, Manipur, India

\section{SN Chishti}

Professor and Head of

Department of Orthopaedics,

Regional Institute of Medica

Sciences, Imphal, Manipur, India

Dr. Herojeet Takhellambam

Post Graduate Trainee,

Department of Orthopaedics,

Regional Institute of Medical

Sciences, Imphal, Manipur, India

Dr. Chanderpaul G

Post Graduate Trainee,

Department of Orthopaedics,

Regional Institute of Medical

Sciences, Imphal, Manipur, India

Dr. Mikachi Jajao D Shira

Post Graduate Trainee,

Department of Orthopaedics,

Regional Institute of Medical

Sciences, Imphal, Manipur, India

\section{Epidemiology of distal radius fracture in adults: A prospective study for 2 years in RIMS, Imphal}

\author{
Dr. G Rishikanta Sharma, Dr. Mhasesalu Tetseo, SN Chishti, Dr. Herojeet \\ Takhellambam, Dr. Chanderpaul G and Dr. Mikachi Jajao D Shira
}

DOI: https://doi.org/10.22271/ortho.2021.v7.i2k.2707

\section{Abstract}

Introduction: Distal radius fracture is one of the most common fractures encountered by an orthopaedician in daily practice. But because of lack of data, the causative factors especially in the developing and underdeveloped countries are not being understood and thus making its management difficult. The purpose of this study is to bridge this knowledge gap.

Materials and Method: A hospital based prospective longitudinal study in RIMS, Imphal, Orthopaedic department for 2 years. All patients with distal radius fracture and willing to participate were included in the study. Data including history and physical examination were collected and patients followed up at regular interval and functional assessment of the wrist done.

Result: Distal radius fracture was found to be more common in older age group (mean-57.1yrs) and female sex. Low energy fall was the most common mode of injury and fracture was more common on the left wrist. The DASH score at final follow-up was $8.61 \pm 0.07$.

Conclusion: Increased incidence of distal radius fracture with low energy fall in older age group and female sex may be attributed to decreased bone mineral density as in post menopausal osteoporosis. Conservative management given to all patients as majority patients had extra articular fracture and within acceptable limit. But open reduction and internal fixation is recommended for displaced intra articular and unstable fracture.

Keywords: distal radius fracture, causative factors, osteoporosis

\section{Introduction}

Distal radius fractures are among the most common fractures encountered in clinical practice with increasing incidence in many parts of the world for reasons not fully understood and likely multi-factorial. Many of the societal effects of these fractures extend beyond the significant medical costs and include loss of work hours, loss of independence, lasting disability and also decreased school attendance in paediatric patients. Yet few epidemiologic studies of distal radius fracture have been published and mostly involved western developed population.

The various studies done did not infer on sex as a risk factor as there were variable results in the studies depending upon the study population. But there was significant association between men and high energy fractures owing likely to motor vehicle accidents ${ }^{[1,2]}$. An increase in the incidence of distal radius fracture with age was seen ${ }^{[2]}$ however a decreasing trend in the incidence was also noted ${ }^{[1,4]}$. Osteoporosis was a common risk factor seen in almost all the studies done. ${ }^{1-3}$ Most distal radius fractures were found to be of extra-articular type ${ }^{[2,5]}$. The conservative mode of management was the most common treatment modality employed ${ }^{[1,4]}$.

As mentioned, although multiple epidemiological studies have been done in developed countries, there is lack of data within developing and under-developed countries. And as it is said, prevention of any ailment is the best treatment, understanding the epidemiology will help identify risk factors and create awareness through different health programs, policies and acts regarding lifestyle modification, regular check-up of medical and surgical co-morbidities and health consciousness. Thus, possessing a knowledge of the incidence and outcomes of the distal radius fracture allows the physician to better counsel the patients and determine the best management to optimize the treatment.
Corresponding Author: Dr. Mhasesalu Tetseo Post Graduate Trainee, Department of Orthopaedics, Regional Institute of Medical Sciences, Imphal, Manipur, India 
Although treatment outcomes for young adults and paediatric population are fairly well defined, recent studies and researches in the elderly has made decision making for the patient and surgeon more complex.

The purpose of this study is to fill this knowledge gap. The epidemiological data including age, sex, mode of injury, hand dominance, mode of treatment can help guide treatment and prevention of these fractures.

\section{Materials and Method}

This is a hospital based prospective longitudinal study in the out patient, emergency and wards of the department of Orthopaedics, RIMS, Imphal, Manipur, conducted from August 2018 to July 2020. All patients of age 18-90years with distal radius fracture attending the RIMS ortho department and willing to participate in the study were included. Informed written consent and ethical clearance from institution was taken.

The patients were thoroughly examined to evaluate their general physical condition, mode of injury alongwith their detailed history. The fracture was further assessed with antero-posterior and lateral X-ray. Then the patients were subjected to closed reduction after checking the vascular and neurological status.

Closed manipulation was done under intramuscular injection of diclofenac sodium and mild sedation. The patients were kept in supine position with shoulder abducted and elbow flexed. Reduction was done using Charnley's method, which comprises of disimpaction by hyperextension and followed by immediate volar extension and pronation to lock the fragments. Traction was maintained by two assistants, while the residual deformity was corrected by manipulation and plaster of paris slab was applied. The slab was changed to neutral in 3 weeks and removed by the $6^{\text {th }}$ week and instructed to initiate range of movement exercises immediately.

Patients were followed up at $3^{\text {rd }}$ week, $6^{\text {th }}$ week, $3^{\text {rd }}$ month and $6^{\text {th }}$ month postoperatively. All findings were recorded in every visit, functional assessment and radiological assessment of fracture progression done.

Functional assessment: Range of motion of affected hand was measured. The patients were asked to complete a DASH questionnaire at each follow up visit and the score obtained at their first visit served as the post injury baseline level of function. The questionnaire contains a 30-item querying symptoms and function related to arm pathology. It is scored from 0-100 with a higher score indicating greater disability.

Secondary outcomes were measured beginning six weeks after initiation of treatment, and included measurement of wrist and forearm motion. Forearm supination and pronation were assessed with the elbow flexed at 90 degrees at the patient's side. And wrist flexion and extension and radioulnar deviation assessed with a goniometer.

\section{Data management and statistical analysis}

1. Data checked for completeness and consistency

2. Data entered and analysed using Statistical Package for Social Sciences (SPSS)

3. V.21 for Windows (IBM corp., Armonk, NY, USA)

4. Descriptive data presented in the form of mean, standard deviation

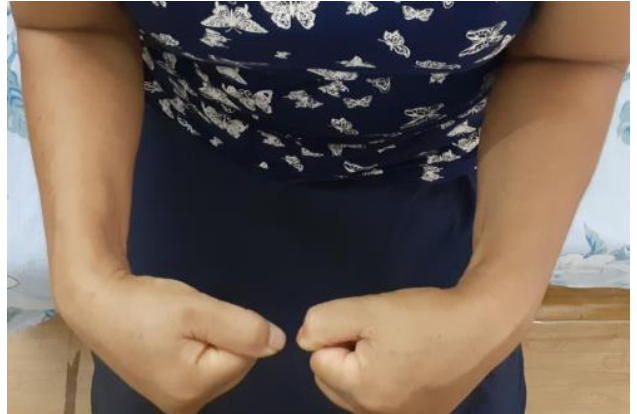

Fig 1: wrist flexion at final evaluation

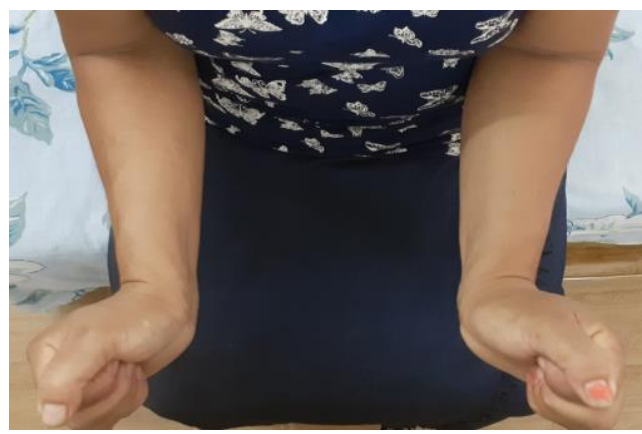

Fig 2: wrist extension at final evaluation

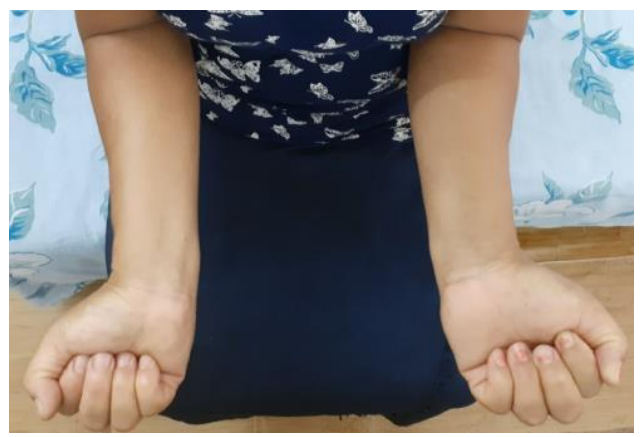

Fig 3: Radial deviation at final evaluation

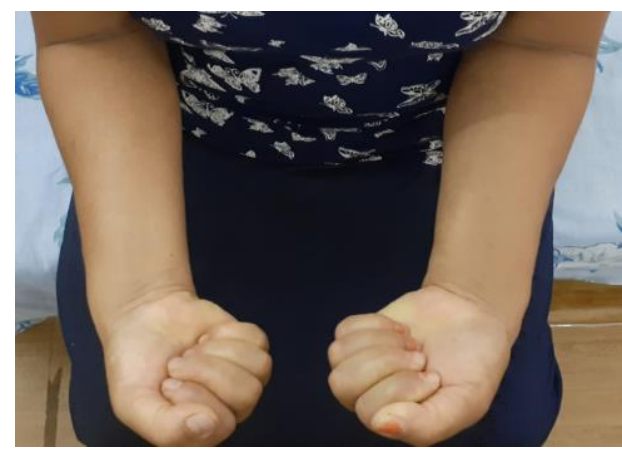

Fig 4: Ulnar deviation at final evaluation

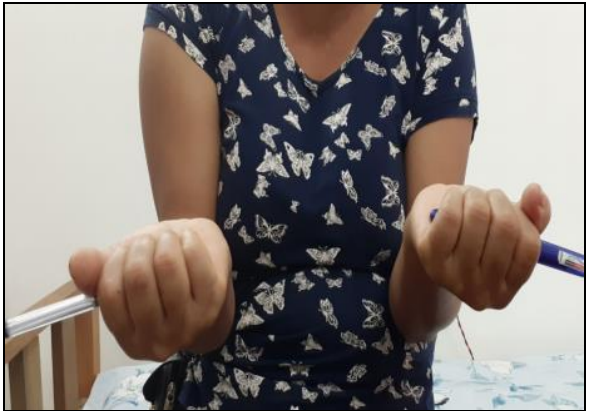

Fig 5: Supination 


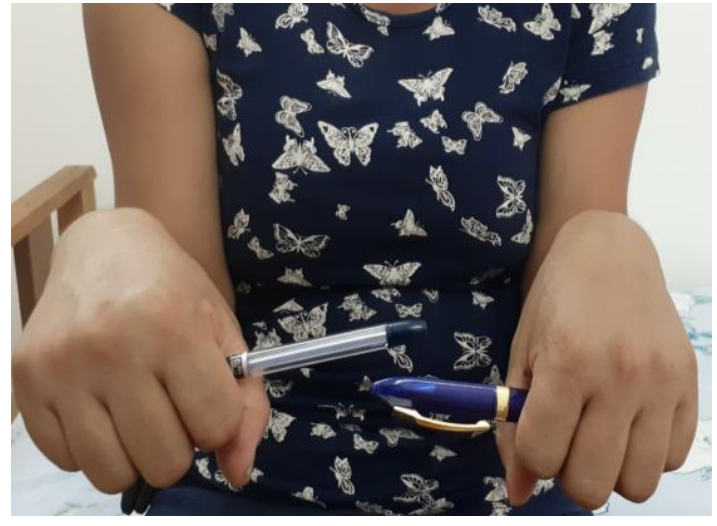

Fig 6: Pronation

\section{Results and observations}

105 adult patients with distal radius fracture were treated in the department of Orthopaedics, Regional Institute of Medical Sciences, Imphal in the period between August 2018 and July 2020. The following results and observations were made at the end of the study.

\section{Age distribution}

The mean age of the patients was $57.1 \pm 17.1$ years (range 1890). The age group of 59-78years consisted of the highest number of patients $(45.7 \%)$ with distal radius fracture, with female patients consisting the maximum in this age group. Male patients were maximum in the younger age group i.e. $18-38 y r s$ age group. Fig 9 shows the percentage in different age groups.

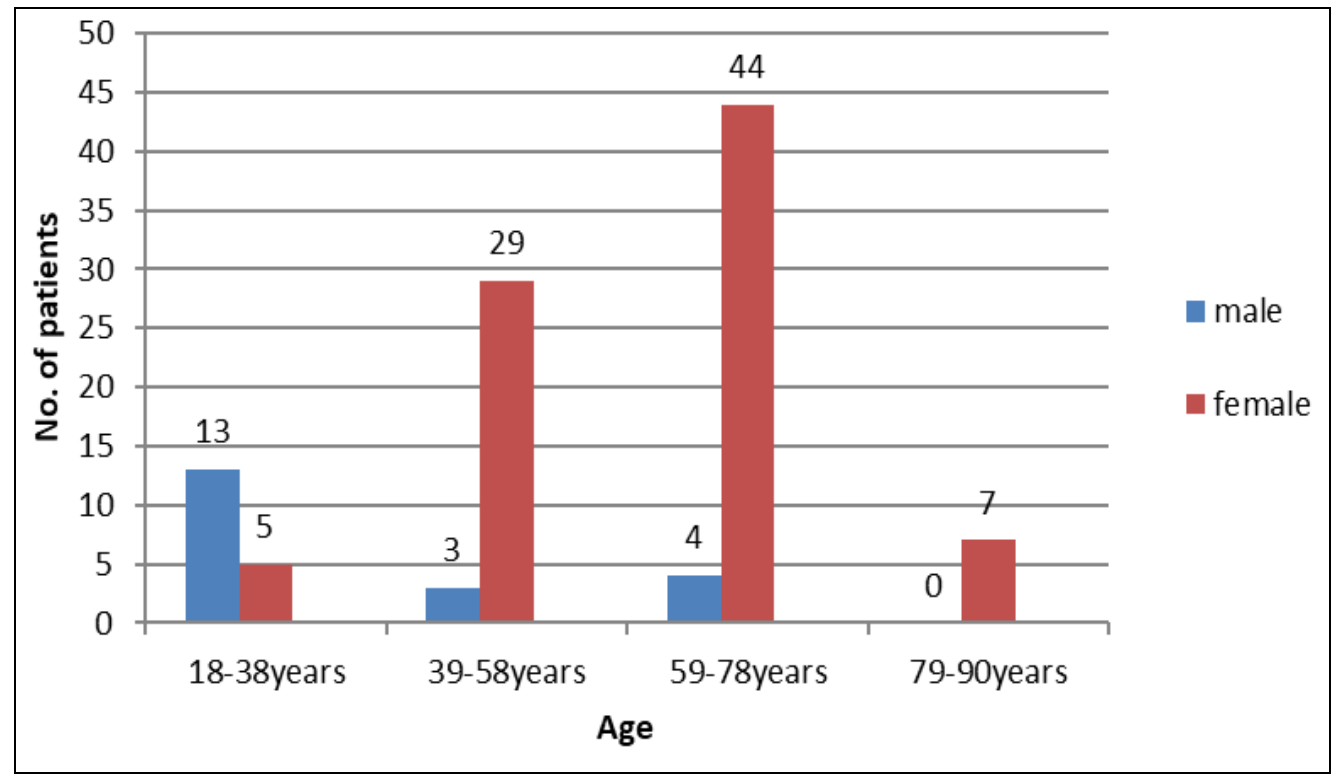

Fig 9: Age- Sex distribution $(\mathrm{N}=105)$

Distribution of fracture side

Right side was involved in $16(15.2 \%)$ patients and left side was involved in $89(84.8 \%)$ patients out of which right side was the dominant side in all the patients.

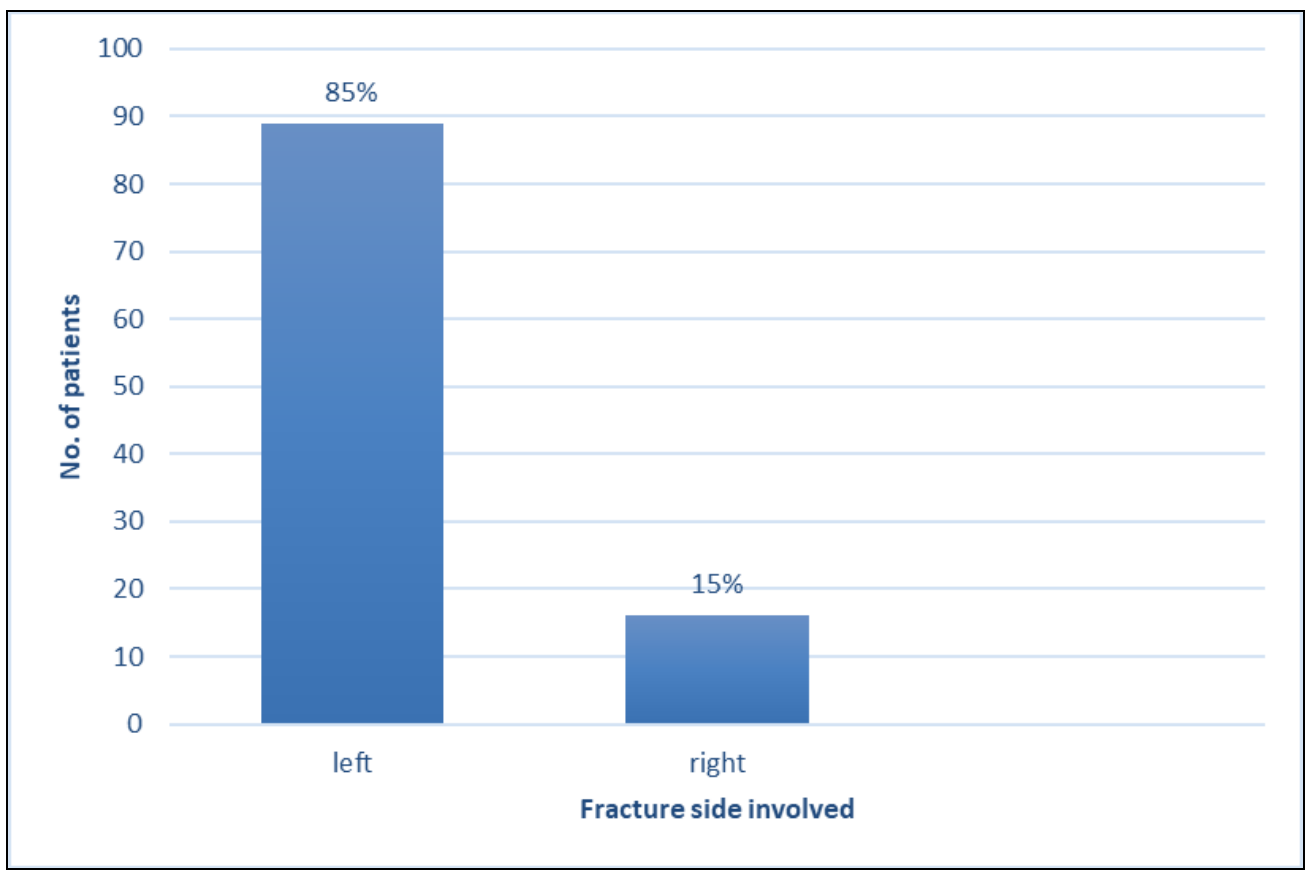

Fig 10: Distribution of fracture side involved $(\mathrm{N}=105)$ 


\section{Mode of injury}

Fall on outstretched hand accounted for 87 (82.9\%) fractures and Road traffic accidents accounted for 18(17.1\%) fractures.

Fig 11 shows distribution of cases with mode of injury.

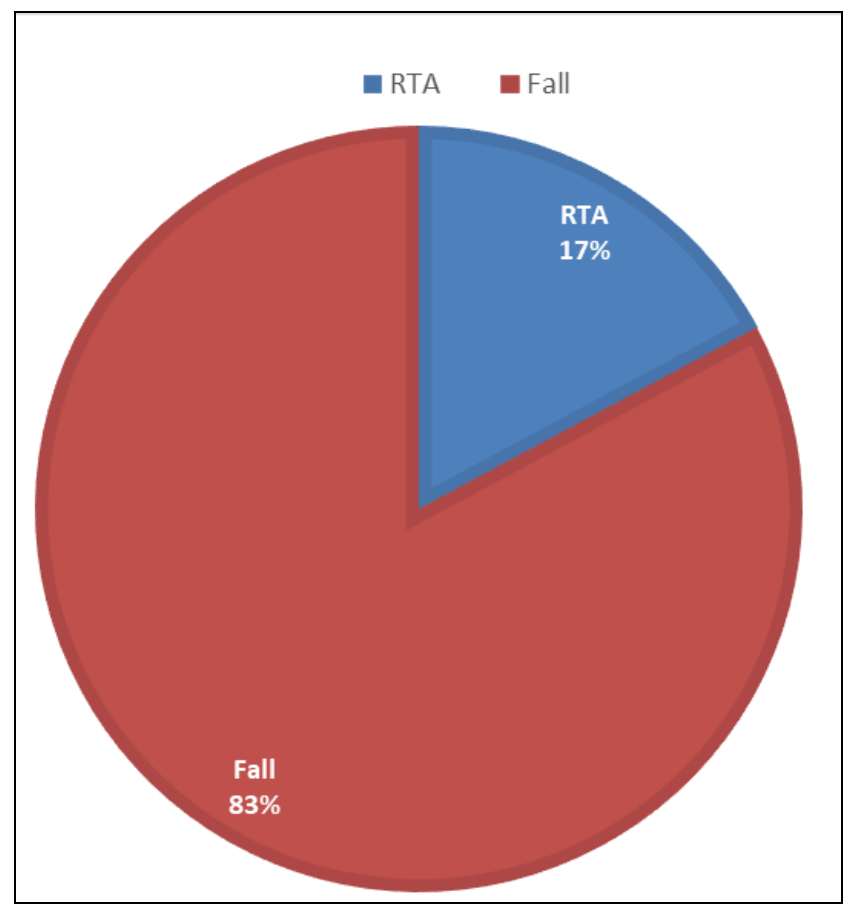

Fig 11: Mode of injury $(\mathrm{N}=105)$

\section{Fracture classification}

Classifying fractures according to AO (Arbeitsgemeinschaft fur Osteosynthesefragen) classification, 83(79\%) cases were type A(Extra-articular), 16(15.2\%) cases were type B (Partialarticular) and 6(5.7\%) cases were type C (Complete articular). Fig 12 shows the distribution of cases based on $\mathrm{AO}$ classification.

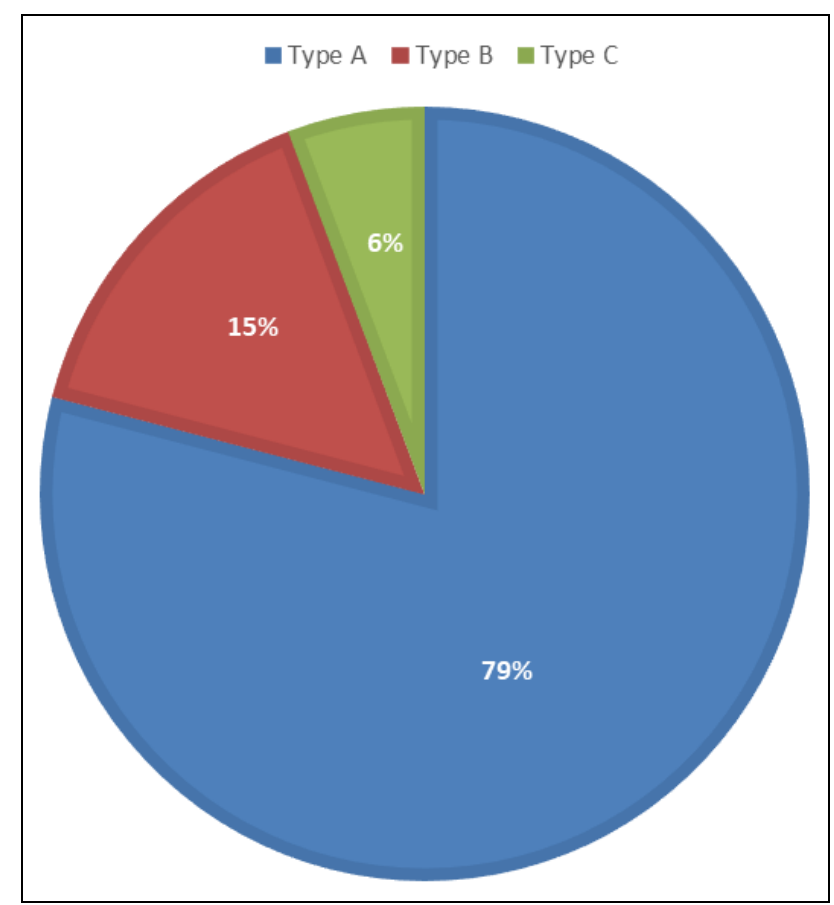

Fig 12: Distribution of cases with respect to AO classification $(\mathrm{N}=105)$

\section{Time of fracture union}

The mean time to sound clinical union was $6.28 \pm 0.52$ weeks (range 5-7 weeks) in all the cases and 7.34 \pm 0.8 weeks (range 6-9 weeks) for radiological union. Table 1 shows the duration and mean duration of clinical as well as radiological union.

Table 1: Time of fracture union

\begin{tabular}{|c|c|c|}
\hline Type of union & Duration(weeks) & Mean duration \pm SD $^{*}$ \\
\hline Clinical & $5-7$ & $6.28 \pm 0.52$ \\
\hline Radiological & $6-9$ & $7.34 \pm 0.8$ \\
\hline
\end{tabular}

*Standard Deviation (SD)-a measure of the amount of variation or dispersion of a set of values

\section{Final range of motion achieved}

Average range of motion achieved by the patients at final follow up were an wrist extension averaged at $66^{\circ}$ (range 40 80 ), wrist flexion $65^{\circ}$ (range $40-80$ ), radial deviation $13^{\circ}$ (range 5-20), ulnar deviation $25^{\circ}$ (range 10-40), forearm supination $65^{\circ}$ (range 40-90), and forearm pronation $65^{\circ}$ (range 10-40). At final examination, all the patients had full finger flexion and finger extension.

Table 2: Final range of motion of wrist achieved

\begin{tabular}{|c|c|c|}
\hline ROM & $\begin{array}{c}\text { Final range (in } \\
\text { degrees) }\end{array}$ & $\begin{array}{c}\text { Final } \\
\text { ROM } \pm \text { SD* }\end{array}$ \\
\hline Wrist extension & $40-80$ & $66 \pm 9.1$ \\
\hline Wrist flexion & $40-80$ & $65 \pm 8.8$ \\
\hline Radial deviation & $5-20$ & $13 \pm 3.9$ \\
\hline Ulnar deviation & $10-40$ & $25 \pm 7.7$ \\
\hline Forearm supination & $40-90$ & $65 \pm 10.3$ \\
\hline Forearm pronation & $40-90$ & $65 \pm 10.4$ \\
\hline
\end{tabular}

*Standard Deviation (SD)

\section{Functional assessment}

Based on the Disabilities of Arm, Shoulder and Hand score (DASH score) for the present study, the mean DASH score at the end of 24 weeks was $8.61 \pm 0.07$ (range 7-10). The DASH score ranges from 0-100 with lower numbers indicating a better outcome or lesser disability. Fig 13 shows the decreasing trend of the mean DASH score.

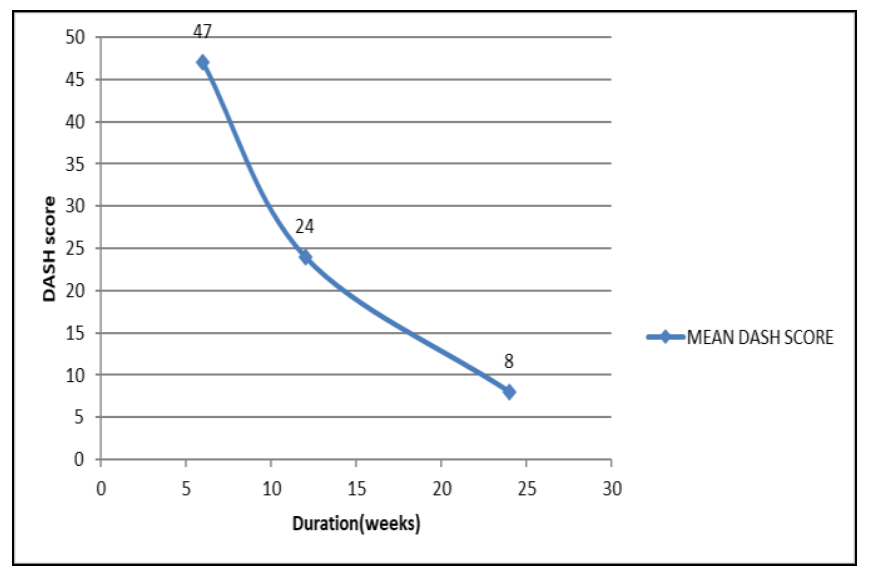

Fig 13: Mean DASH score $(\mathrm{N}=105)$

\section{Discussion}

One hundred and five adult patients with distal radius fracture, out of which all patients underwent conservative management, were followed up in the department of Orthopaedics, RIMS Imphal between August 2018 to July 2020.

Patients were in the age group 18-90years with the mean age of 57.1years. The age group 59-78 years consisted of the highest number of patients $(45.7 \%)$. This is similar to the findings of Koo KOT ${ }^{[2]}$ et al where out of 431 patients, the 
fractures peaked at 50-60years age group, Rozenthal TD et al ${ }^{[6]}$ where the mean age of 41 patients was 53years, and KK Wong et al. ${ }^{[7]}$ where the mean age group was 58.6 years. Keeping in mind the age group where the highest number of patients were seen, the fractures seemed to peak around the perimenopausal age where osteoporosis is a common risk factor.

In this study, there were 20 males (19\%) and 85 females $(81 \%)$ where females were found to be more. Studies by Diamantopoulos AP et al. ${ }^{[1]}$ and Sigurdardottir K et al ${ }^{[4]}$ also found higher incidence in females. Findings of Dillingham $\mathrm{C}$ et $a l^{8}$ where 15 women and 12 men were included in the study also supplemented to this study's findings. This finding where the higher incidence was in females may also be attributed to osteoporosis.

Low energy fall on outstretched hand consisted of 87 (82.9\%) fractures while high energy road traffic accidents consisted of only $18(17.1 \%)$ fractures. Koo KOO et al, ${ }^{[2]}$ SolgaardS et al. ${ }^{[9]}$ and Orbay JL et al ${ }^{[10]}$ reported similar findingswhere the main cause of distal radius fracturewas fall on outstretched hand which is a low energy trauma and may be attributed to decreased bone mineral density as in osteoporotic bone and may be related with increased incidence in females.

Also, in this study majority of the patients had distal radius fracture on the left side $(84.8 \%)$ out of which all were on the non-dominant side. In only 16 patients (15.2\%), the dominant right side was involved and was present only in high energy associated trauma in this study. This is similar to the result of Falch JA ${ }^{[11]}$ where about $55 \%$ of the fractures were left sided. As also opined by Falch JA, this increase in left sided incidence, especially with low energy trauma, was maybe due to tendency to protect oneself while falling with the left hand as a result of the right hand being used to carry goods, etc.

On classifying the fractures according to the AO (Arbeitsgemeinschaft fur Osteosynthesefragen) classification, Type A (Extra articular) accounted for 83 (79\%) fractures, Type B(Partial articular) accounted for 16(15.2\%) fractures and type $\mathrm{C}$ (Intra articular) accounted for only $6(5.7 \%)$ fractures. With Type A fractures being the maximum fracture type may have contributed to the good mean functional outcome at the final follow up. The result was similar to the findings of Orbay JL et al. ${ }^{[10]}$ where out of 24 distal radius fractures, 17 were Type A and Type B consisted of only 7 fractures.

In this study, the mean time to clinical union of the fracture was 6.28 weeks (range 5-7 weeks). While the mean time for radiological union of the fracture was 7.34 weeks (range 69weeks).

For functional assessment of the limb in this study, DASH score was used to assess the patients. The mean DASH score at the final follow up ( 24 weeks) of the 105 study patients was $8.61 \pm 0.07$ (range 7-10). The perfect DASH score for a limb being " 0 " with range for normal extremity being 4-8. Complications like malunion, stiffness, chronic pain were found in minimal patients.

Short study period with insufficient follow up duration was a limitation of this study.

\section{Conclusion}

As is evident in this study and supported by multiple other precedent studies on this subject, females especially in the older age group are commonly seen with distal radius fracture with the most common mode of injury being fall on outstretched hand, which may be attributed to decreased bone mineral density as in postmenopausal osteoporosis. On the other hand, males were more commonly involved, as compared to females, in the younger age group which may be attributed to their more active lifestyle and more likely involvement in high energy road traffic accidents.

Also, incidentally all of our study cases were treated conservatively as majority of the cases were not indicated for surgery and in indicated cases, the patients were unfit for surgery. The fractures were managed conservatively by immobilising in plaster of paris casts, which gave satisfactory functional outcome at the final follow up of 24 weeks. However, we recommend open reduction and internal fixation for the displaced intra articular and unstable fractures.

We encountered complications of malunion, stiffness, chronic pain in minimal patients. However, traumatic osteoarthritis could not be documented due to the short term follow up. Therefore, for most intra articular and unstable fractures, longer follow up is necessary.

\section{References}

1. Diamantopoulos AP, Rohde G, Johnsrud I, Skoie IM, Hochberg M, Haugeberg G. The epidemiology of lowand high-energy distal radius fracture in middle aged and elderly men and women in Southern Norway. PLoS ONE [serial online] 2012;7(8):[7]. Available from https://doi.org/10.1371/journal.pone.0043367. Accessed on 24 June, 2018.

2. Koo KOT, Tan DMK, Chong AKS. Distal Radius Fractures: An Epidemiological Review. Orthopaedic Surg 2013;5:209-13.

3. Kwon GD, Jang SM, Lee AR, Park CM, Lee YK, Kim TY et al. Incidence and Mortality after Distal Radius Fractures in adults aged 50 years and older in Korea. J Korean Med Sci 2016;31(4):630-34.

4. Sigurdardottir K, Halldorsson S, Robertsson J. Epidemiology and treatment of distal radius fractures in Reykjavik, Iceland, in 2004. Acta Orthop 2011;82(4):494-98.

5. Harper CM, Fitzpatrick SK, Zurakowski D, Rozental TD. Distal Radial Fractures in Older Men- A missed opportunity? J Bone Joint Surg Am 2014;96:1820-7.

6. Rozenthal TD, Blazar PE. Functional outcome and complications after volar plating for dorsally displaced, unstable fractures of distal radius. J Hand Surg 2006;31(A):359-65.

7. Wong KK, Chan KW, Kwok TK, Mak KH. Volar fixation of doesally displaced distal radius fracture using locking compression plate. J Orthop Surg 2005;13(2):153-7.

8. Dillingham C, Horodyski M. Rate of improvement of volar plate reduction and internal fixation of distal radius fractures. Adv Orthop 2011;2011:565-642.

9. Solgaard S, Petersen VS. Epidemiology of distal radius fractures. Acta Orthop Scand 1985;56:391-93.

10. Orbay JL, Fernandez DL. Volar Fixed- Angled Plate fixation for unstable distal radius fractures in the elderly patients. J Hand Surg 2004;29(A):96-102.

11. Falch JA. Epidemiology of Fractures of the Distal Forearm in Oslo, Norway. Acta Orthop Scand $1983 ; 54: 2,291-95$. 